\title{
EQUILIBRIUM AND KINETIC STUDIES OF PHENOL SORPTION BY CHITOSAN COATED MONTMORILLONITE
}

\author{
JINLONG YAN* AND GUIXIANG QUAN
}

\author{
School of Chemical and Biological Engineering, Yancheng Institute of Technology, Yancheng 224003, China
}

(Received 25 June 2008 - Accepted 11 August 2008)

\begin{abstract}
In order to provide physical support for chitosan and increase the accessibility of the binding sites for sorption process applications, chitosan was coated on the surface of montmorillonite. For the optimization of the sorption of phenol on chitosan coated montmorillonite (CCM), effects of $\mathrm{pH}$, initial concentration and temperature on the sorption of phenol by CCM were investigated. In order to find the sorption characteristics, the isothermal data were applied to Langmuir and Freundlich linear isotherm equation, and the thermodynamic parameters $(\Delta H, \Delta G$ and $\Delta S)$ were also calculated according to the values of binding Langmuir constant $K_{\mathrm{L}}$. The L type sorption isotherm between phenol and CCM suggests a relatively high affinity between the adsorbate and adsorbent, and the mechanism involved in the association of phenol with CCM were proton transfer, hydrogen bonding, London-Van der Waals forces because of lots of the $\mathrm{OH}_{\text {and }} \mathrm{NH}_{2}$ groups in the chitosan chain. The negative $\Delta H$ constant confirmed that the more phenol was adsorbed by CCM at lower temperature and the driving force for sorption process is an enthalpy effect. The kinetics of the sorption process of phenol on CCM were also investigated using the pseudo-first order and pseudo-second order kinetics, results showed that the second order equation model provided the best correlation with the experimental results. It was reached that modification of chitosan with montmorillonite increased the possibility of utilization of chitosan for phenol remove from aqueous solution.
\end{abstract}

Keywords: Sorption; Chitosan; Phenol; Kinetics; Equilibrium

\section{INTRODUCTION}

Phenols are common soil and groundwater pollutants. These chemicals are classified as priority pollutants due to their toxic health effects at very low concentrations. Phenols in soil and groundwater are derivatives of natural biogeochemical processes or have their origins in anthropogenic materials such as pesticide mixtures. Soils contaminated with anthropogenic phenols are of specific environmental concern because of the ecological risk associated with their high toxicity and relatively high mobility in the soil and groundwater environment. The ingestion of such contaminated water in the human body causes protein degeneration, tissue erosion, and paralysis of the central nervous system and also damages of the kidney, liver and pancreas. The threshold value of phenol in water is $4000 \mu \mathrm{g} / \mathrm{L}^{1}$. Therefore, it is considered necessary to remove the phenol form industrial effluents before discharging into the water stream. Sorption is superior in simplicity of design, initial cost, ease of operation and insensitivity to toxic substances in comparation with other physicochemical and biological techniques, such as the membrane filtrations coagulation/flocculation, ion exchange, advanced oxidation (chlorination, ozonation), flotation, chemical reduction and biological treatment (bacterial and fungal biosorption, biodegradation in aerobic or anaerobic conditions) $)^{2}$. Several investigations have studied the sorption of phenol on active carbon because of its large surface area, micro-porous nature, high adsorption capacity, high purity and easy availability ${ }^{3-7}$.

Natural materials that are available in large quantities or certain waste form agricultural operations may has potential to be used as low cost adsorbents, as they represent unused resources, widely available and are environmentally friendly. Chitosan (2-amino-2-deoxy- $\beta$-D-glucan) is a partially deacetylated polymer of chitin by deacetylation with a strong alkaline solution. Many attention have been focused on the remove of trace metals from water by chitosan because of the coordination betweens the metal and the $\mathrm{NH}_{2}$ groups in the chitosan chain ${ }^{8}$, and the sorption of phenol from aqueous solution and its affecting parameters were also reported in our previous study ${ }^{9}$, but it is slightly soluble at low pHs and poses problems for developing commercial applications. It is also soft and has a tendency to agglomerate or form a gel in aqueous solutions. In addition, the active binding sites of chitosan are not readily available for sorption. Transport of the contaminants to the binding sites plays a very important role in process design. Therefore, it is necessary to provide physical support and increase the accessibility of the binding sites for process applications $\mathrm{s}^{10,11}$.

Clays are widely used as adsorbents due to their high specific surface area. On the other hand, their sorption capacity is very low for organic molecules that are highly water soluble, polar, or cationic. This is due to the hydrophilic nature of the mineral surfaces. Natural clay has a negative charge that is compensated by exchangeable cations, such as $\mathrm{Na}^{+}$and $\mathrm{Ca}^{2+}$ on their surfaces. This study concerns the applicability of montmorillonite as a physical support for coating chitosan to remove phenol. Over the last 20 years, several studies have been carried out on the use of quaternary ammonium salt exchanged clays as adsorbents of many organic compounds from water ${ }^{12}$.

In the present investigation an attempt was made to overcome these mass transfer limitations by synthesizing a biosorbent by coating chitosan on the surface of montmorillonite and evaluating its equilibrium sorption properties. The combination of the useful properties of montmorillonite and that of natural chitosan, could introduce a composite matrix with many application and superior sorption capabilities. Batch studies are carried out involving process parameters such as the effects of $\mathrm{pH}$, the initial phenol concentration, temperature and contact time. Equilibrium analysis was conducted to understanding sorption process.

\section{METERIALS AND METHODS}

\section{Chemical reagents}

Na-montmorillonite used was provided by 184 Bentonite Company of the $10^{\text {th }}$ Agriculture Division of Xinjiang Construction Group in China, which is a fine powder with an average particle size of $75 \mu \mathrm{m}$ in the dry state, a purity of $90 \%$, an interlayer spacing of $1.44 \mathrm{~nm}$, and a cation exchange capacity (CEC) of $92 \mathrm{mmol} / 100 \mathrm{~g}$. Stock solution of $1000 \mathrm{mg} / \mathrm{L}$ phenol (AR) was prepared with distilled water and stored in a refrigerator. Working solutions were prepared by diluting the stocking solution with distilled water just prior to use. Chitosan with the deacetylation degree $88 \%$ was obtained from Kabo Co. (Shanghai, China), which was ground and sieved to $100-150$ mesh. The viscosity [ $\eta]$ of chitosan in $0.1 \mathrm{~mol} / \mathrm{L} \mathrm{CH}_{3} \mathrm{COONa}+0.2 \mathrm{~mol} / \mathrm{L} \mathrm{CH}_{3} \mathrm{COOH}$ solution was determined by the NDT- 1 type viscometer at $30 \pm 0.1 \square$. The weight-average molecular weight was calculated by Mark-Houwink equation ${ }^{11}:[\eta]=k M_{\mathrm{w}}{ }^{\alpha}$, where $\alpha=-1.02 \times 10^{-2} \times \mathrm{DD}+1.82, \mathrm{k}=1.64 \times 10^{-30} \times \mathrm{DD}$, and $\mathrm{DD}$ is the degree of deacetylation of chitosan. The weight-average molecular mass $\left(M_{\mathrm{w}}\right)$ of sample used in this experiment is 280,000 .

\section{Preparation of chitosan coated montmorillonite (CCM)}

One gram montmorillonite was ground into paste in $100 \mathrm{~mL}$ deionized water, and then added in $100 \mathrm{ml} 2 \mathrm{~g} / \mathrm{L}$ chitosan solution with constant stirring for $1 \mathrm{~h}$ at $25 \square$. The $\mathrm{pH}$ of the solution was adjusted to 7.0-7.5 with $20 \mathrm{~g} / \mathrm{L}$ sodium hydroxide solution and then was precipitated for $0.5 \mathrm{~h}$ at $25 \square$. The resulting CCM was filtered and washed with deionized water, and then dried at 40 $\square$. XRD data was obtained using a DX-2000/DX-2500 X-ray diffractometers (Dandong, China) at room temperature without any further heat treatment. \%OC (organic carbon)value of $\mathrm{CCM}$ was measured with $\mathrm{HCl}$ $(10 \%, \mathrm{~V} / \mathrm{V})$ using a CNS Macro Elemental Analyzer (Elementar Analysen Systeme GmbH, Germany). The specific surface areas of montmorillonite and CCM were determined by using BET method after $\mathrm{N}_{2}$ adsorption-desorption at 77 K with Sorptomatic 1990, Germany.

\section{Equilibrium studies}

The sorption experiments were performed by batch method where samples of $0.1 \mathrm{~g}$ of CCM were equilibrated with $50 \mathrm{~mL}$ of solution containing various amount of phenol, under an intermittent stirring. Solutions $\mathrm{pH}$ was 
adjusted by using diluted solution of $\mathrm{NaOH}$ or $\mathrm{HCl}$. The temperature $(25 \square$, $35 \square$ and $45 \square$ ) of the thermostatic bath was controlled within $\pm 0.5 \square$. In pH dependent experiments, the phenol concentration was constant at $40 \mathrm{mg} / \mathrm{L}$ for each sample. After a determined time (usually $24 \mathrm{~h}$ ), the suspensions were centrifuged at $5000 \mathrm{rpm}$ for $20 \mathrm{~min}$, the concentration of phenol in the clear supernatant was determined using spectrophotometrically measurements. A SP1105E 721-model spectrophotometer (Shanghai, China) was used throughout for the concentration determination of phenol at wavelength $510 \mathrm{~nm}$ using 4-aminoantipyrine as the chromogenic reagent. The $\mathrm{pH}$ measurements were carried out with a $25 \mathrm{pHS}-2 \mathrm{C}$ model acidity meter (Leici Instrumental Factory, Shanghai, China), using a combination electrode.

The sorption capacity of CCM $\left(q_{e}\right)$ was evaluated by amount of phenol sorbed: $q_{e}=\left(C_{0}-C_{e}\right) \times V \times 10^{-3} / G$, (mg of phenol /g of sorbent) and by percent of phenol removal: $R \%=\left(C_{0}-C_{e}\right) \times 100 / C_{0}$, where: $C_{0}$ and $C_{\mathrm{e}}$ are initial and the equilibrium concentration of phenol in solution $(\mathrm{mg} / \mathrm{L}), G$ is amount of sorbent $(\mathrm{g})$ and $V$ is volume of solution $(\mathrm{mL})$.

\section{Kinetic studies}

Effect of contact time was determined by the "limited bath" technique. A sample $(1 \mathrm{~g})$ of CCM was added to $500 \mathrm{~mL}$ volume of phenol solution, with initial phenol concentration $40 \mathrm{mg} / \mathrm{L}$. Under stirring, the temperature of solution was held constant at $25^{\circ} \mathrm{C}$ with a thermostatic bath and solutions $\mathrm{pH}$ was adjusted to 4.0 by using diluted solution of $\mathrm{NaOH}$ or $\mathrm{HCl}$. After different time intervals (from 30 minutes to 24 hours), volumes of $1 \mathrm{~mL}$ supernatant were taken for spectrophotometrically measurements of phenol content.

\section{RESULTS AND DISCUSSIONS}

\section{Characterization of CCM}

XRD data was used to see the basal peak and investigated the $d_{001}$ value, there was no difference with the $d_{001}$ values of montmorillonite and CCM, which meant that chitosan could not enter the interior channels of montmorillonite. $\% \mathrm{OC}$ value of $\mathrm{CCM}$ was found to be 5.22 , the specific surface areas of montmorillonite and CCM were $256 \mathrm{~m}^{2} / \mathrm{g}$ and $187 \mathrm{~m}^{2} / \mathrm{g}$, respectively. The amount of chitosan deposited on the surface of montmorillonite was calculated theoretically to be about $11.5 \%$ in CCM when chitosan was assumed to be with the formula $\left(\mathrm{C}_{8} \mathrm{H}_{13} \mathrm{NO}_{5}\right)_{\mathrm{n}}$.

\section{Optimization of the sorption of phenol on CCM}

$\mathrm{pH}$ is an important parameter for adsorption of phenol from aqueous solution because it affects the solubility of phenol, concentration of the counter ions on the functional groups of the adsorbent and the degree of ionization of the adsorbate during reaction. To examine the effect of $\mathrm{pH}$ on the phenol removal efficiency, the $\mathrm{pH}$ was varied from 2.0 to 10.0. The amount of phenol adsorbed show a declining trend with higher as well as with lower $\mathrm{pH}$, and the maximum removal of phenol (more than $88 \%$ by the adsorbents) was observed at $\mathrm{pH} 4.0$ (Figure 1). Several researchers have studied the sorption-desorption of phenolic chemicals in soil-water and sediment-water systems ${ }^{13-15}$. Phenols have been found to possess relatively high mobility in the aquifer environment because their sorption to mineral surfaces were usually minimal ${ }^{16}$, soil organic matter (SOM) was found to be a dominant factor that influenced the fate of organic contaminants in soils and aquifer material ${ }^{17,18}$, so the sorption of phenol by $\mathrm{CCM}$ was mainly contributed to chitosan. At low $\mathrm{pH}$ (below 4.0), the amine group on chitosan is protonated to varying degree but phenol is not dissociated because phenol is a very weak acid and has resonance stability due to its anionic structure (the $\mathrm{p} K_{\mathrm{a}}$ value of phenol is 9.98). Simultaneously physical and chemical adsorption were known as sorption, so the results indicated at $\mathrm{pH}$ 4.0 the chemical affinity between the $\mathrm{OH}$ and $\mathrm{NH}_{2}$ groups in the structure of chitosan and the $\mathrm{OH}$ group in the structure of phenol reached the top. Non-polar portions play an important role in hydrophobic interactions, the mechanism involved in the association of phenol with CCM were proton transfer, hydrogen bonding, London-Van der Waals forces because of lots of the $\mathrm{OH}$ and $\mathrm{NH}_{2}$ groups in the chitosan chain.

The sorption capacity of the powdered adsorbent CCM for phenol was determined at different initial phenol concentrations. The results presented in Table 1 shown that the phenol amount adsorbed increased with increasing phenol concentration but the percent of phenol removal decreased. At low initial phenol concentration, the ratio of the number of phenol ions to the number of available adsorption sites was small and consequently the sorption was independent of the initial concentration, but as the concentration of phenol increased, the situation changes and the competition for adsorption sites became fierce. As a result, the extent of sorption came down considerably, but the amount adsorbed per unit mass of the adsorbent rose.

The sorption capacity of the powdered adsorbent CCM for phenol was determined at different temperature (Table 1). It indicated that less phenol was adsorbed at high temperature. The effect of ionic strength to sorption of phenol was also examined, sorption capacities of CCM for phenol increased with the increased in ionic strength.

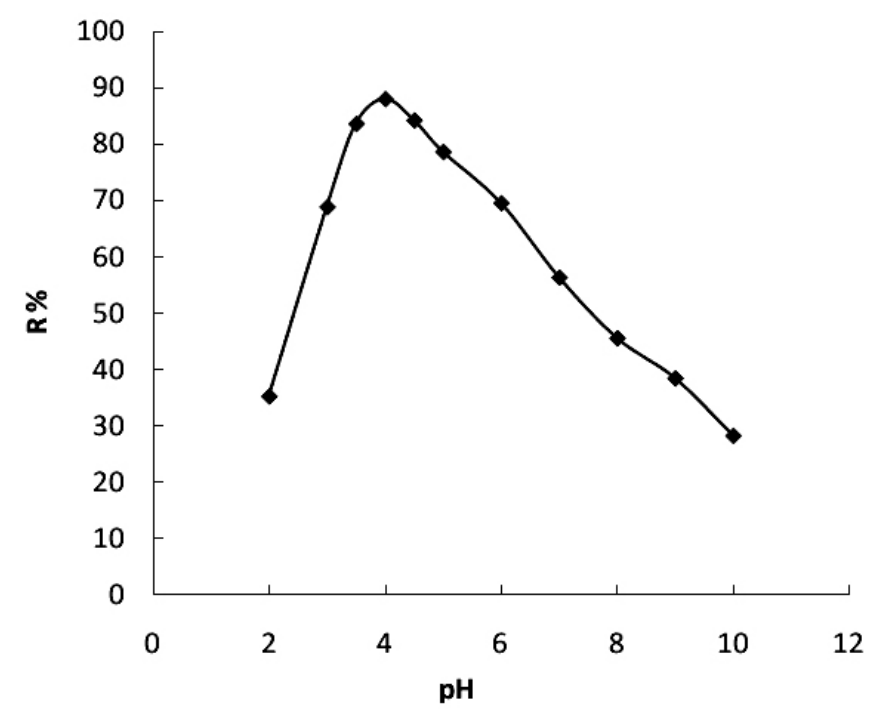

Figure 1. The influence of $\mathrm{pH}$ value on the sorption of the phenol on CCM.

Table 1. The influence of temperature on the sorption of phenol on $\mathrm{CCM}^{*}$

\begin{tabular}{|c|c|c|c|c|}
\hline $\begin{array}{c}\text { Temperature } \\
(\square)\end{array}$ & $\boldsymbol{C}_{\mathbf{0}}(\mathbf{m g} / \mathbf{L})$ & $\boldsymbol{C}_{\mathbf{e}}(\mathbf{m g} / \mathbf{L})$ & $\boldsymbol{q}_{\mathbf{e}}(\mathbf{m g} / \mathbf{g})$ & $\boldsymbol{R}(\mathbf{\%})$ \\
\hline \multirow{4}{*}{$\mathbf{2 5}$} & 20 & 1.23 & 9.38 & 93.8 \\
\cline { 2 - 5 } & 40 & 4.78 & 17.61 & 88.1 \\
\cline { 2 - 5 } & 60 & 12.24 & 23.88 & 79.6 \\
\cline { 2 - 5 } & 80 & 23.02 & 28.49 & 71.2 \\
\cline { 2 - 5 } & 100 & 43.28 & 28.36 & 56.7 \\
\hline \multirow{4}{*}{35} & 20 & 2.03 & 8.99 & 89.8 \\
\cline { 2 - 5 } & 40 & 6.12 & 16.94 & 84.7 \\
\cline { 2 - 5 } & 60 & 15.24 & 22.38 & 74.6 \\
\cline { 2 - 5 } & 80 & 28.98 & 25.51 & 63.8 \\
\hline \multirow{4}{*}{45} & 100 & 49.76 & 25.12 & 50.2 \\
\hline & 20 & 2.64 & 8.68 & 86.8 \\
\hline & 40 & 8.03 & 15.99 & 79.9 \\
\cline { 2 - 5 } & 60 & 18.07 & 20.97 & 69.9 \\
\cline { 2 - 5 } & 80 & 32.8 & 23.60 & 59.0 \\
\cline { 2 - 5 } & 100 & 54.13 & 22.94 & 45.8 \\
\hline
\end{tabular}

* $C_{0}$ : initial concentration of phenol; $C_{\mathrm{e}}$ : equilibrium concentration of phenol; $q_{e}$ : sorption capacity of CCM; $R \%$ : percent of phenol removal. 


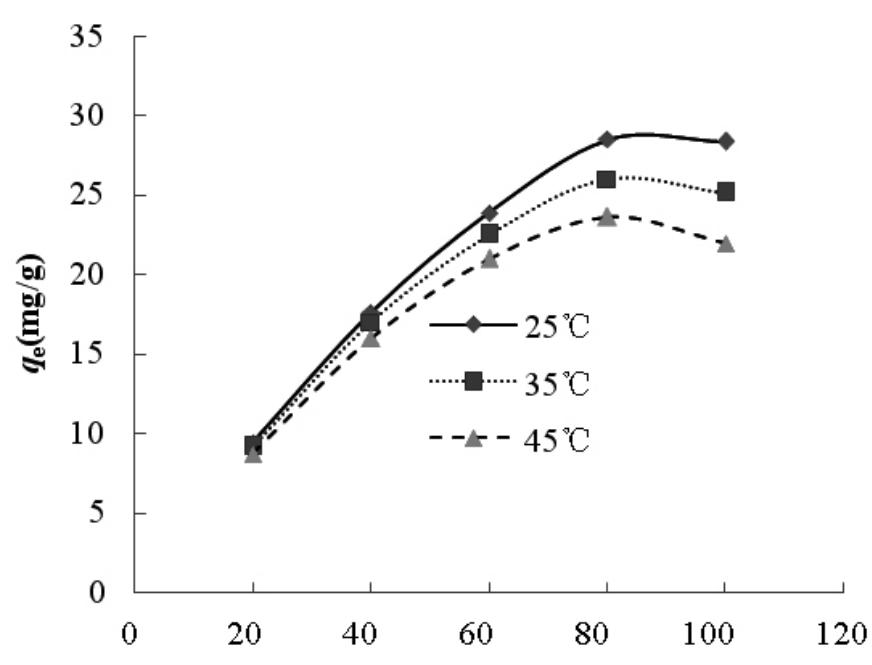

$C \mathrm{e}(\mathrm{mg} / \mathrm{L})$

Figure 2. Sorption isotherms for phenol sorption on CCM at $25 \square, 3 \square$ and $45 \square$.

$C_{\mathrm{e}}$ : equilibrium concentration; $q_{e}$ : sorption capacity of CCM

\section{Sorption isotherms}

Isotherms were the equilibrium relation between the concentration of the adsorbate on the solid phase and in the liquid phase. Phenol adsorption isotherms for CCM were drawn as the amount of phenol adsorbed as a function of equilibrium phenol concentration and shown in Figure 2. In terms of the slope of the initial portion of the curves, the shapes of the isotherms corresponding to $25 \square, 35 \square$ and $45 \square \quad$ may be classified as $L$ type isotherm of Giles classification ${ }^{19}$. All of these curve shown convex initial curvature reaching a saturation plateau at a definite value. The $\mathrm{L}$ type isotherm suggested a relatively high affinity between the adsorbate and adsorbent. A competition may be seen for the sorption sites between water and phenol. Generally, L type isotherm reflected the occurrence of chemisorption.

To optimize the design of an sorption system for the removal of adsorbates, it was important to establish the most appropriate correlation for the equilibrium curves. Experimental data related to the sorption of phenol by chitosan was applied to the Freundlich equation ${ }^{20}$,

$$
q=k C_{\mathrm{e}}^{1 / n}
$$

where $k$ parameter was relative to the sorption capacity and $n$ was a measure of sorption intensity; a favorable sorption corresponded to a value of $1<n<10$.

The linear form of Freundlich equation was used to interpret the results in the following form,

$$
\log q=\log k+1 / n \log C_{\mathrm{e}}
$$

Binding parameters of phenol on CCM, which were calculated from intercepts and slopes of these plots, were presented in Table 2, together with the correlation coefficient $\left(r^{2}\right)$ as a goodness of fit criterion. As can be seen from the results of linear form of Freundlich equation, the $n$ values of the phenol sorption isotherms on CCM confirmed L-shape. Based on the linear form of Freundlich equation, greater $k$ value was used to like sorption at lower temperature.

Experimental data related to the adsorption of phenol by CCM was also applied to the Langmuir isotherm equation ${ }^{20}$,

$$
\begin{aligned}
& q=K_{\mathrm{L}} C q_{0} /\left(1+K_{\mathrm{L}} C_{\mathrm{e}}\right) \\
& 1 / q=1 / q_{0}+1 /\left(K_{\mathrm{L}} q_{0}\right) \cdot 1 / C_{\mathrm{e}}
\end{aligned}
$$

where $K_{\mathrm{L}}$ was related to energy of the sorption and $q_{0}$ was the maximum value of sorption capacity(corresponding to complete monolayer coverage).
The values in Table 2 show that the experimental data were more suitable to the Langmuir model than the Freundlich model. This was in accordance with the shape of the sorption isotherms, which corresponded to type $\mathrm{L}_{2}$ (Langmuir type) in the Giles classification system for sorption of a solute from its solution ${ }^{19}$.

\section{Thermodynamic study}

As seen from Table 2 the values $q_{0}$ of maximum sorption capacity, corresponding to monolayer coverage of the binding sites available in the sorbent, was obtained at different temperature. In the range $25-45 \square$ an decrease of $q_{0}$ was found with the increasing temperature.

Using the values of binding Langmuir constant $K_{\mathrm{L}}$, and the following equations, one can calculate the thermodynamic parameters $(\Delta \mathrm{H}, \Delta \mathrm{G}, \Delta S)$ (Table 3) of phenol sorption on CCM,

$$
\begin{aligned}
& \ln K_{L}=-\Delta H /(R \mathrm{~T})+\text { constant } \\
& \Delta G=-\mathrm{RT} \ln K_{\mathrm{L}} \\
& \Delta S=(\Delta H-\Delta G) / \mathrm{T}
\end{aligned}
$$

The negative values of apparent free energy change $(\Delta \mathrm{G}, \mathrm{kJ} / \mathrm{mol})$ confirmed that the sorption process of phenol on CCM was a spontaneous process. The negative apparent enthalpy change $(\Delta \mathrm{H}, \mathrm{kJ} / \mathrm{mol})$ computed from the slope of linear dependence of $\log K_{\mathrm{L}}$ on $1 / \mathrm{T}$ confirmed that more phenol was adsorbed by $\mathrm{CCM}$ at lower temperature. The negative apparent entropy change $(\triangle \mathrm{S}$, $\mathrm{J} / \mathrm{mol} \mathrm{K}$ ) characterized a decreased disorder of the system and the apparent entropy change values were almost. It can be suggested that the driving force for sorption process was an enthalpy effect.

Table 2. The characteristic parameters of sorption process of phenol on CCM.

\begin{tabular}{|c|c|c|c|c|c|c|}
\hline \multirow{2}{*}{$\begin{array}{c}\text { Temperature } \\
(\square)\end{array}$} & \multicolumn{3}{|c|}{$\begin{array}{c}\text { Freundlich linear } \\
\text { isotherm }\end{array}$} & \multicolumn{3}{c|}{ Langmuir linear isotherm } \\
\cline { 2 - 7 } & $k$ & $n$ & $r^{2}$ & $\begin{array}{c}q_{0} \\
(m g / g)\end{array}$ & $K_{L}(L / g)$ & $r^{2}$ \\
\hline 25 & 9.68 & 3.096 & 0.940 & 29.41 & 377.8 & 0.993 \\
\hline 35 & 8.65 & 3.205 & 0.912 & 27.78 & 283.5 & 0.997 \\
\hline 45 & 7.31 & 3.155 & 0.869 & 26.32 & 188.1 & 0.994 \\
\hline
\end{tabular}

Table 3. The apparent thermodynamic parameters of sorption process of phenol on CCM

\begin{tabular}{|c|c|c|c|}
\hline $\mathrm{T}(\mathrm{K})$ & $\Delta G(\mathrm{~kJ} / \mathrm{mol})$ & $\Delta H(\mathrm{~kJ} / \mathrm{mol})$ & $\Delta S(\mathrm{~J} / \mathrm{mol} \cdot \mathrm{K})$ \\
\hline 298 & -14.70 & & -42.61 \\
\hline 308 & -14.46 & \multirow{2}{*}{-27.40} & -42.01 \\
\hline 318 & -13.75 & & -42.63 \\
\cline { 1 - 1 } & & & \\
\hline
\end{tabular}

Table 4. The kinetic parameters of sorption process of phenol on CCM

\begin{tabular}{|c|c|c|c|c|}
\hline \multicolumn{2}{|c|}{$\begin{array}{c}\text { Pseudo-first order } \\
\text { lagergren model }\end{array}$} & \multicolumn{3}{|c|}{ Pseudo-second order model } \\
\hline $\mathrm{k}_{1}$ & $\mathrm{r}^{2}$ & $\mathrm{k}_{2}$ & $\mathrm{~h}$ & $\mathrm{r}^{2}$ \\
\hline 0.0065 & 0.9772 & $7.66 \times 10^{-4}$ & 0.3499 & 0.9968 \\
\hline
\end{tabular}




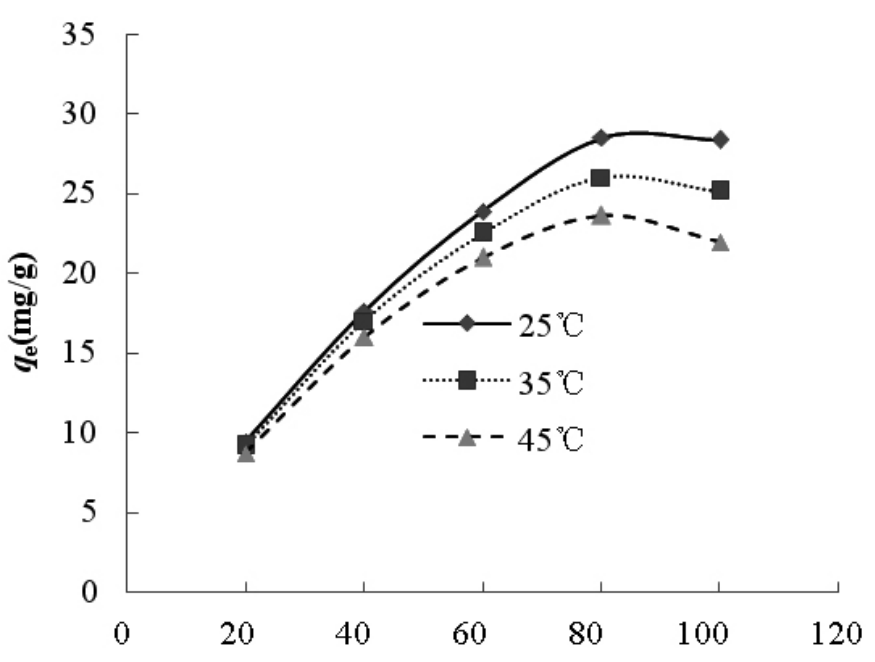

$C \mathrm{e}(\mathrm{mg} / \mathrm{L})$

Figure 3. The effect of contact time on removal of phenol on CCM.

\section{Kinetic study of the adsorption}

Effect of contact time on removal of phenol on CCM was shown in Figure 3. Sorption results revealed fast uptake of adsorbate species at the initial stages of the contact period, a gradual slow down as it approached equilibrium, with more or less a constant rate of adsorption at the intermediate stage. The values of the residual concentrations at $6 \mathrm{~h}$ contact time was found to be almost same than those obtained after $24 \mathrm{~h}$ contact time. As seen in Figure 3, the equilibrium period required for maximum removal was found to be 4-6 hours. However the sorption half-time $\left(t_{1 / 2}\right)$ were of 45-60 min. This effect may probably be because of more available surfaces in the initial stage for adsorption leading to faster rate, in contrast to final stage where available adsorption site might have reduced with increasing repulsive force by already adsorbed particles, thus resulting in slow rate of adsorption.

The numerical analysis of sorption kinetic models assuming external mass transfer and intra-particle diffusion (pore diffusion, surface diffusion) was frequently applied to describe the sorption kinetics in batch systems theoretically. However, the complicated mathematical computation limited their use from the viewpoint of engineering applications. Therefore, some lumped kinetic models such as the pseudo-first-order, pseudo-secondorder, and Elovich equations were adopted to simulate the kinetic data. The kinetics of the sorption process of phenol on CCM was investigated using two different models, the pseudo-first order and pseudo-second order kinetics ${ }^{1}$. The pseudofirst order lagergren model, traditionally used for describing sorption kinetics, is generally expressed by the equation,

$$
\log \left(q_{0}-q_{\mathrm{t}}\right)=\log \left(q_{0}\right)-k_{1} \mathrm{t}
$$

Where $k_{1}$ was the lagergren rate constant of the first order sorption, evaluated from the slope of the plot $\log \left(q_{0}-q_{t}\right)$ versus $\mathrm{t}, \mathrm{mg} /(\mathrm{g} \bullet \mathrm{min})$.

According to the pseudo-second order model, the kinetics was described by the equation,

$$
\mathrm{t} / q_{\mathrm{t}}=1 /\left(k_{2} q_{0}^{2}\right)+\mathrm{t} / q_{0}
$$

Where $k_{2}$ was the rate constant of the second order sorption, $\mathrm{g} /(\mathrm{mg} \bullet \mathrm{min})$ and $k_{2} q_{0}{ }^{2}=h$ was the initial sorption rate, $\mathrm{mg} /(\mathrm{g} \cdot \mathrm{min})$. By plot $\mathrm{t} / q_{\mathrm{t}}$ versus $\mathrm{t}$, a straight line could be obtained and $q_{0}, k_{2}$ and $\mathrm{h}$ can be calculated.

The experimental kinetic data were adjusted according to the indicated models and the coefficients of correlation as well as the kinetic parameters of phenol on CCM were given in Table 4. The results showed that the second order equation model provided the best correlation with experimental results. This finding was similar to other studies on the biosorption of several dyes. For instance, pseudo second-order kinetics was also observed in the biosorption of Remazol Black B on biomass ${ }^{20}$.

\section{CONCLUSIONS}

For the sorption of phenol by CCM on the basis of the experimental results obtained, the sorption with maximum sorption capacity must be conducted at high concentration, low temperature, and $\mathrm{pH}=4.0$. The $\mathrm{L}$ type sorption isotherm between phenol and CCM suggested a relatively high affinity between the adsorbate and adsorbent, and the mechanism involved in the association of phenol with CCM were proton transfer, hydrogen bonding, London-Van der Waals forces because of lots of the $\mathrm{OH}$ and $\mathrm{NH}_{2}$ groups in the chitosan chain. The negative $\Delta H$ constant at lower temperature confirmed that more phenol is adsorbed by CCM at lower temperature, and the driving force for sorption process is an enthalpy effect. The kinetics of the sorption process of phenol on CCM was investigated using the pseudo-first order and pseudo-second order kinetics; results showed that the second order equation model provided the best correlation with the experimental results. From the standpoint of industrial applications, CCM was suitable and attractive adsorbent due to low price and high sorption capacity.

\section{REFERENCES}

1. R. Qadeer, A.H. Rehan, Turk. J. Chem. 26, 357, (2002)

2. D. Suteu, D. Bilba, Acta Chim. Slov. 52, 73, (2005)

3. E. Costa, G. Calleja, L. Marjuan, Adsorp. Sci. Technol. 5, 213, (1988)

4. M. Kastelan-Malan, S. Cerjan-Stefanovic, M. Petrovic, Chromatographic. 27, 297, (1989)

5. S. Biniak, J. Kazmierczak, Adsorp. Sci. Technol. 6, 182, (1989)

6. N.S. Abuzeid, I.M. Harrozim, J. Envirn. Sci. Health A. 26, 257, (1991)

7. K. Radeke, H.D. Loseh, K. Struve, E. Weiss, Zeolites. 13, 69, (1993)

8. M. Y. Lee, K. J. Hong, Y. Shin-Ya, T. Kejiuchi, J. Appl. Polym. Sci. 96, $44,(2005)$

9. J.L. Yan, Chin. J. Polymer Sci. 24, 497, (2006)

10. S. Babel, T. A. Kurniawan, Chemosphere. 54, 951, (2004)

11. W. Wang, S. Bo, S. Li, W. Qin, Int. J. Biol. Macromol. 13, 281, (1991)

12. M. Houari, B. Hamdi, J. Brendle, J. Hazard. Mater. 147, 738, (2007)

13. P. J. Isaacson, C. R. Frink, Environ. Sci. Technol. 18, 43, (1984)

14. K. G. Robinson, J. T. Novak, Water Res. 28, 445, (1994)

15. B. Xing, W. B. McGill, M. J. Dudas, L.G. Hepler, C. Dobrogowska, Chemosphere CMSHAF. 26, 1311, (1993)

16. I. Sabbah, M. Rebhun, Water Environ. Res. 69, 1032, (1997)

17. P. M. Gschwend, S.C. Wu, Environ. Sci. Technol. 19, 90, (1985)

18. L. S. Lee, P. S. C. Rao, P. Nkedi-Kkizza, Environ. Sci. Technol. 24, 654, (1990)

19. C.H. Giles, T.H. McEwan, S.N. Nakhwa, D. Smith, J. Chem. Soc. 4, 3973, (1960)

20. C. H. Ko, C.H Fan, P.N. Chiang, M.K. Wang, K.C. Lin, J. Hazard. Mater. 149, 275, (2007). 